\title{
Controle de papuã (Urochloa plantaginea) e produtividade de milho em solo argiloso através de formulação e doses de atrazina com liberação controlada
}

\author{
Control of alexandergrass and maize yield in a clay soil through concentrations \\ and controlled release formulation and doses of atrazine

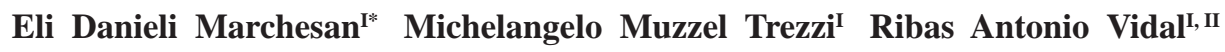 \\ Deborah Pinheiro Dick ${ }^{\mathrm{III}}$ Gabrieli Dedordi ${ }^{\mathrm{I}}$ Elouize Xavier ${ }^{\mathrm{I}}$
}

RESUMO

A utilização de herbicidas com formulações com liberação controlada poderá se constituir em uma ferramenta importante para reduzir problemas de lixiviação e garantir a eficácia desses produtos. O objetivo do presente trabalho foi comparar a eficiência de controle de Urochloa plantaginea (UROPL) e o rendimento de grãos de milho entre uma formulação de atrazina comercial (WG) e uma formulação de liberação controlada (xerogel). O delineamento utilizado foi o de blocos ao acaso, em parcelas subdivididas, com quatro repetições, em um esquema $(2 \times 7)+1$. Nas parcelas principais, foram locadas as formulações de atrazina (WG e xerogel) e, nas subparcelas, as concentrações dos herbicidas (0, 2400, 3200, 3600, 4200, 5400 e $8000 \mathrm{~g}$ de atrazina $\mathrm{ha}^{-1}$ ). Foram determinados os níveis de controle e densidade de plantas de UROPL e o rendimento de grãos da cultura do milho. A elevação das doses de atrazina resultou em aumento dos níveis de controle de UROPL. Em avaliações realizadas aos 28 e 35 dias após a aplicação, a atrazina xerogel demonstrou eficiência agronômica superior à formulação WG. Não ocorreram diferenças de rendimento de grãos de milho em parcelas tratadas com diferentes formulações e níveis de atrazina.

Palavras-chave: Zea mays, controle químico, herbicida de solo, xerogel.

\section{ABSTRACT}

The use of herbicides with controlled release formulations may constitute important tool to reduce leaching problems and increase the efficacy of atrazine in soil. The aim of this study was to compare the efficiency of control of Urochloa plantaginea (UROPL) and corn grain yield from a commercial formulation (WG) of atrazine and a controlled-release formulation (xerogel). The design was randomized blocks in split plots with four replications in a scheme $(2 \times 7)+1$. Factor A consisted of the formulations of atrazine (WG and xerogel), factor $B$ concentrations of herbicide (0, 2400, 3200, 3600, 4200, 5400 and 8000ha atrazine $\left.\mathrm{g}^{-1}\right)$. Variables assessed consisted of control levels, plant density of UROPL and corn grain yield. The increasing levels of atrazine resulted in increased levels of control UROPL. In assessments made at 28 and 35 days after application, atrazine xerogel showed higher agronomic efficiency than the WG formulation. There were no differences in corn grain yield from plots treated with different formulations and atrazine levels.

Key words: Zea mays, chemical control, soil herbicide, xerogel.

\section{INTRODUÇÃO}

A produção de milho no Brasil tem grande importância econômica, social e geográfica, sendo uma atividade bem difundida, com presença em todos os estados brasileiros. A maior produção brasileira de milho ocorre nos Estados do Sul, a qual corresponde de $44 \%$ a $54 \%$ do total brasileiro (TESTA \& SILVESTRO, 2010).

A interferência de plantas daninhas na cultura do milho pode ocasionar redução no seu crescimento e desenvolvimento, alem da produtividade de grãos, podendo inviabilizar economicamente a lavoura (BALBINOT et al., 2009). Lavouras de milho sem controle de plantas daninhas podem ter a produtividade reduzida entre 12 e 100\% (SALES, 1991). Quando Urochloa plantaginea (UROPL) não é controlada, a redução da produtividade de grãos em lavouras de milho pode chegar a 90\% (VIDAL et al., 2004).

IPrograma de Pós-graduação em Agronomia (PPGAG), Universidade Tecnológica Federal do Paraná (UTFPR), 85503-390, Pato Branco, PR, Brasil. E-mail: elidanieli_marchesan@yahoo.com.br. *Autor para correspondência.

IIPrograma de Pós-graduação em Fitotecnia, Universidade Federal do Rio Grande do Sul (UFRGS), Porto Alegre, RS, Brasil.

IIIDepartamento de Físico-Químca, Instituto de Química, UFRGS, Porto Alegre, RS, Brasil. 
Para o controle de plantas daninhas ocorrentes em milho, pode-se usar a atrazina (2-cloro-4-etilamino-6-isopropilamino-s-triazina), herbicida da família das s-triazinas (FLECK \& VIDAL, 2001), que controla plantas daninhas dicotiledôneas e monocotiledôneas em aplicação pré-emergente e em pós-emergência inicial. Esse grupo de herbicidas é muito utilizado nas culturas de milho, sorgo e cana-de-açúcar. Há inúmeros relatos de casos de contaminação dos lençóis freáticos ao se usar atrazina, principalmente na América do Norte e na Europa (ÁVILA et al., 2009). No Brasil, são relatados na literatura casos de contaminação de águas superficiais e subterrâneas com esse herbicida (PESSOA, et al., 2003; CERDEIRA et al., 2005).

O uso de formulações com liberação controlada pode ser uma alternativa para diminuir o impacto ambiental, provocado pelos herbicidas. A liberação controlada visa a amenizar os problemas apresentados pelas formulações convencionais. Buscam-se formulações menos tóxicas e mais eficazes por retardarem a liberação do ingrediente ativo, com aumento da persistência para maior eficiência no controle de plantas daninhas (SOUZA, 1999). Assim, sistemas de liberação controlada de atrazina podem ser mais eficientes tanto do ponto de vista agronômico, quanto ecológico e econômico (FERNÁNDEZ-PÉREZ et al., 2001; AKELAH et al., 2008). Dentre os métodos de liberação controlada, está o xerogel, que envolve a formação de uma matriz inorgânica que esteja em condições brandas e permite que as moléculas sejam incorporadas no interior ou se distribuam na superfície de um gel. Pela secagem do gel e por evaporação espontânea do solvente, obtém-se um material chamado xerogel (BARBOSA et al., 2010).

Hipotetiza-se que a atrazina xerogel, comparativamente à formulação comercial de atrazina, controla a infestação de plantas daninhas por tempo mais longo, resultando em maior produtividade de grãos de milho. Objetivou-se com o trabalho comparar a eficiência de controle de UROPL e a produtividade de grãos de milho com a utilização das formulações e doses de atrazina comercial (WG) e de liberação controlada (xerogel).

\section{MATERIAL E MÉTODOS}

O experimento foi instalado a campo na Área Experimental da Universidade Tecnológica Federal do Campus Pato Branco - PR, localizada no

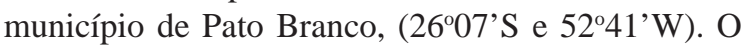
solo é classificado, segundo o sistema brasileiro de classificação de solos (EMBRAPA, 2006), como um
Latossolo Vermelho distroférrico. O clima, de acordo com a classificação de Köppen, é subtropical úmido com verão quente (Cfa).

O delineamento utilizado foi blocos ao acaso, em parcelas subdivididas, com quatro repetições, em um esquema $(2 \times 7)+1$. Nas parcelas principais, foram locadas as formulações (atrazina comercial - COM e atrazina xerogel - XER) e, nas subparcelas, as concentrações de atrazina $(0,2400$, 3200, 3600, 4200, 5400 e $8000 \mathrm{~g} \mathrm{ha}^{-1}$ ) tiveram acréscimo de quatro parcelas testemunha capinadas. A formulação $C O M$, em grânulo dispersível em água (WG), denomina-se GENIUS ${ }^{\circledR}$. Já a formulação $X E R$ foi sintetizada no Instituto de Química da Universidade Federal do Rio Grande do Sul.

As subparcelas foram constituídas de cinco linhas de milho, espaçadas entre si de $0,7 \mathrm{~m}$ e com $7 \mathrm{~m}$ de comprimento para o tratamento comercial $\left(24,5 m^{2}\right)$ e $3 \mathrm{~m}$ de comprimento $\left(10,5 \mathrm{~m}^{2}\right)$ para o tratamento $X E R$. A área útil de cada subparcela foi composta pelas três linhas centrais, descontando-se $0,5 \mathrm{~m}$ das extremidades frontais e laterais de cada linha.

Os herbicidas foram aplicados em préemergência, logo após a semeadura da cultura. O híbrido simples de milho (Pioneer 30R50H) foi semeado no dia 13/10/2009, utilizando-se semeadora de precisão, visando à densidade de 67.000 plantas ha-1 . As sementes utilizadas foram previamente tratadas com thiametoxan + fipronil (1,75+0,5g kg-1 sementes). A adubação da área foi procedida de acordo com as necessidades da cultura, através de análise química do solo, utilizando-se 24,60 e $60 \mathrm{~kg} \mathrm{ha}^{-1}$ de $\mathrm{N}, \mathrm{P}_{2} \mathrm{O}_{5}$ e $\mathrm{K}_{2} \mathrm{O}$, respectivamente, através da formulação 8-20-20. Para a adubação de cobertura, foram utilizados $65 \mathrm{~kg} \mathrm{ha}^{-1}$ de $\mathrm{N}$, na forma de ureia, ao lado da linha de semeadura do milho, entre os estádios $\mathrm{V}_{2}$ e $\mathrm{V}_{3}$ (RITCHIE et al., 1993). No momento da aplicação da adubação de cobertura, foi aplicado o inseticida metamidofós (180g i.a para 100L de água) aos 20 dias após a semeadura.

O herbicida na formulação COM foi aspergido ao solo úmido após a semeadura do milho, com pulverizador costal pressurizado com $\mathrm{CO}_{2}$, mantido à pressão constante e munido com cinco pontas de pulverização tipo leque 110.02, distanciadas entre si em $0,50 \mathrm{~m}$, as quais aspergiram um volume de calda de 200 $\mathrm{L} \mathrm{ha}^{-1}$. Como se apresenta em pó e é de difícil diluição em água para sua aplicação nas parcelas a campo, a formulação XER foi misturada a solo da área experimental, previamente seco, triturado e peneirado, na proporção de $2 \mathrm{~kg}$ por subparcela, distribuídos de forma homogênea em cada subparcela. A concentração de XER foi de 
231,9mg g ${ }^{-1}$. A concentração de atrazina para cada subparcela foi calculada pela sua concentração e a distribuição na parcela foi realizada de forma manual.

Foram avaliadas a densidade de plantas daninhas e o controle destas aos 14, 21, 28 e 35 dias após a aplicação do herbicida (DAA). Procedeu-se à identificação e quantificação das plantas daninhas em duas amostras em um quadrado de $0,45 \times 0,45 \mathrm{~m}$, em locais fixados em cada subparcela. A avaliação de controle de plantas daninhas foi procedida atribuindo-se notas que variaram de $0 \%$, para a ausência de controle, a 100\% para controle total das plantas, conforme metodologia descrita por FRANS et al. (1986). A produtividade de grãos da cultura foi determinada através de colheita manual e trilha mecânica do experimento, aos 140 dias após a semeadura. A produtividade de grãos foi determinada pela pesagem dos grãos colhidos na área útil, com correção da umidade para 13\% e extrapolação dos valores para $\mathrm{kg} \mathrm{ha}^{-1}$.

Os dados foram submetidos à análise da variância pelo teste F, com auxílio do programa Winstat. Para o fator formulação, procedeu-se à comparação das médias dos níveis pelo teste DMS a 5\% de probabilidade. As relações entre os níveis de fatores quantitativos e variáveis dependentes foram ajustadas através dos modelos da hipérbole retangular e exponencial decrescente, com auxílio do programa Sigma Plot 10.0.

\section{RESULTADOS E DISCUSSÃO}

$\mathrm{Na}$ área experimental, foram detectadas infestações de papuã (Urochloa plantaginea) (UROPL), leiteiro (Euphorbia heterophylla L.), cordade-viola (Ipomoea purpurea L.), nabo (Raphanus sativus L.) e azevém (Lolium multiflorum L.), havendo grande predominância da primeira espécie. As demais espécies de plantas daninhas não foram avaliadas, pois tiveram seu desenvolvimento muito prejudicado diante da dominância que a UROPL exerceu.

Na análise visual de controle de UROPL, houve significância para o fator dose, em todas as épocas de avaliação e, para o fator formulação, apenas nas avaliações efetuadas aos 14, 28 e 35 dias após a aplicação (DAS). O aumento das doses de atrazina (COM e $X E R)$ resultou em controle crescente de UROPL, que se ajustou ao modelo da hipérbole retangular (Figura 1A, B, C, D). Considerando todas as doses de atrazina testadas, independentemente da formulação empregada, os níveis de controle de UROPL exercidos variaram entre 50 e 85\% (Figura 1). Os níveis de controle obtidos com dose próxima à recomendada de atrazina para o controle de UROPL (4000g ha-1) situaram-se, em todos os períodos, próximos a $70 \%$. Níveis de controle abaixo de $80 \%$ são considerados, na prática, insatisfatórios.

Outros autores verificaram controle satisfatório de UROPL com atrazina, com desempenho variando entre 91 e 95\% (ZAGONEL et al., 2000; MEROTTO JR. et al., 2000). O desempenho pouco satisfatório de atrazina no presente experimento pode ser explicado pelos elevados níveis de infestação de UROPL, que se situaram em média de 680 plantas $\mathrm{m}^{-2}$. Também pode estar relacionado a fatores determinantes do transporte e degradação do herbicida, que podem ter desempenhado papel fundamental na redução da sua disponibilidade para as plantas de UROPL.

Considerando os quatro períodos avaliados, a atrazina comercial proporcionou controle superior apenas na avaliação efetuada aos 14DAA, enquanto que, aos 28DAA e 35DAA, a atrazina xerogel foi mais eficaz, atingindo níveis de controle de 66,8\%, $62,8 \%$ e $62,0 \%$, respectivamente (Tabela 1 ). O maior controle de UROPL nos tratamentos com $X E R$, nas épocas mais tardias de avaliação, provavelmente, são resultantes do período mais longo que essa formulação permaneceu no solo, em função da liberação mais lenta de atrazina. Comparando o controle exercido pela atrazina XER com atrazina de formulação COM no Rio Grande do Sul, BARBOSA et al. (2010) constataram que os níveis de controle de Bidens pilosa variaram entre 80 e 100\%, não apresentando significância entre dose e formulação, enquanto que os níveis de controle de UROPL variaram entre 50 e $85 \%$, para doses entre 2400 e 8000 g ia ha-1.

$\mathrm{Na}$ análise da densidade de UROPL, foi observada significância do fator dose e da interação entre formulação e dose, apenas na contagem efetuada aos 14DAA. Atrazina, aplicada em todas as doses das formulações COM e XER, reduziu a densidade de UROPL, em relação à testemunha infestada, mas foram observadas diferenças significativas entre as formulações apenas no primeiro período de avaliação (Figura 2A). Observa-se, ainda, que, na média das formulações e épocas de avaliação, a maior dose de atrazina (8000 $\mathrm{g} \mathrm{ha}^{-1}$ ) foi capaz de reduzir a densidade de UROPL em cerca de 53\%, quando comparada à testemunha infestada (Figura 2A, B, C, D), embora tenha havido substancial incremento da densidade de UROPL com o decorrer das avaliações, com variações entre formulações (Figura 2).

$\mathrm{O}$ teto de rendimento de grãos de milho obtido foi elevado, atingindo o valor máximo de $11.410 \mathrm{~kg} \mathrm{ha}^{-1}$ (Figura 3). Para essa variável, não

Ciência Rural, v.43, n.11, nov, 2013. 

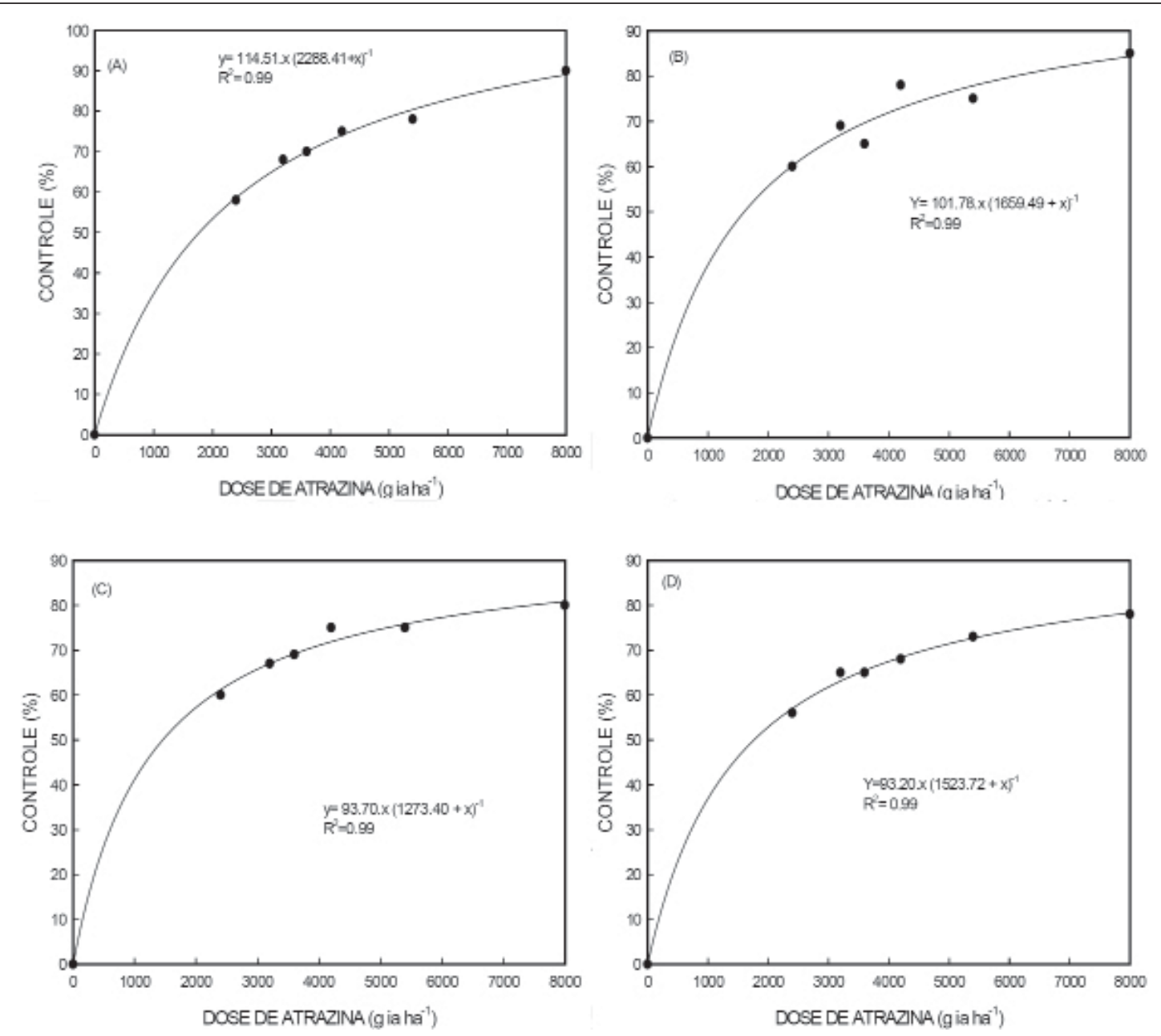

Figura 1 - Avaliação visual do controle de Urochloa plantaginea, em função da época de avaliação, 14(a), 21(b), 28(c), 35(d) dias após a aplicação (DAA), das formulações e das diferentes doses de atrazina. UTFPR, Pato Branco, 2009. Coeficientes de variação: 14DAA (15,87\%), 21DAA (14,88\%), 28DAA (10,33\%), 35DAA (9,54\%).

houve efeito de formulação de atrazina, dose e nem da interação entre formulação e dose. Isso significa que não houve diferenças no rendimento de grãos de milho entre COM e XER, entre a testemunha sem

Tabela 1 - Controle de Urochloa plantaginea pelas formulações WG e xerogel, nas avaliações efetuadas aos 14, 28 e 35 dias após a aplicação (DAA), na média das diferentes doses. UTFPR, Pato Branco, 2009.

\begin{tabular}{llll}
\hline \multirow{2}{*}{ Formulação de atrazina } & \multicolumn{4}{c}{--Controle (\%) de U. Plantaginea-- } \\
& 14DAA & 28DAA & 35DAA \\
\hline Comercial & 66,78 A* & $59,28 \mathrm{~B}$ & $54,28 \mathrm{~B}$ \\
Xerogel & $59,46 \mathrm{~B}$ & $62,85 \mathrm{~A}$ & $61,96 \mathrm{~A}$ \\
\hline
\end{tabular}

*Médias seguidas pela mesma letra na coluna não diferem significativamente pelo teste de DMS $(\mathrm{P}>0,05)$. Coeficientes de variação: 14DAA (15,87\%), 28DAA (10,33\%), 35DAA (9,54\%). controle de plantas daninhas e os tratamentos em que foram aplicadas as formulações de atrazina em diferentes doses, entre as diferentes doses de atrazina e nem em comparação ao controle realizado com capina manual (Figura 3).

O aumento da dose de atrazina não interferiu na produtividade da cultura do milho. No entanto, o uso de uma maior concentração de atrazina refletiria em maior custo para o produtor, podendo também causar maior dano ambiental. Levando-se em conta que o potencial de toxicidade de atrazina para plantas de milho é muito baixo (LÓPEZ-OVEJERO et al., 2003; TREZZI et al., 2005), pode-se inferir que o uso de atrazina não tenha afetado o rendimento da cultura. São raros os casos em que infestações tão elevadas de plantas daninhas, como a observada no presente experimento, não geram redução 

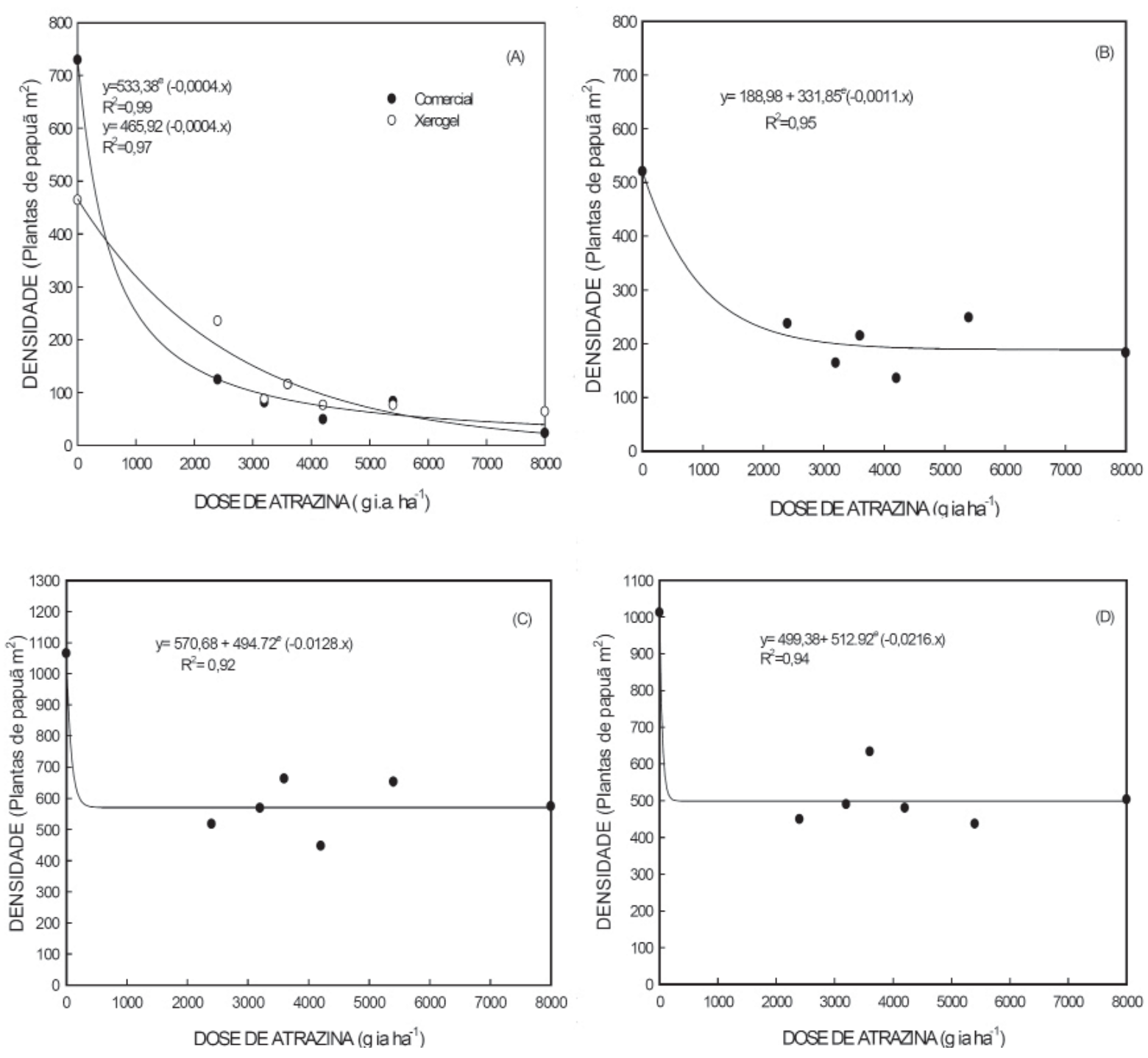

Figura 2 - Densidade de plantas de Urochloa plantaginea: (A) em função da formulação e dos níveis de atrazina; (B, C, D) em função dos níveis de atrazina, na média das formulações WG e xerogel. UTFPR, Pato Branco, 2009. Coeficientes de variação: 14DAA (55,8\%), 21DAA (34,8\%), 28DAA (45,8\%), 35DAA (43,0\%).

significativa de rendimento de grãos de milho. A cultura do milho pode ser consideravelmente afetada pela interferência de plantas daninhas, resultando em redução do crescimento e na produtividade de grãos (SPADER \& VIDAL, 2000; KOZLOWSKI et al., 2009), indicando-se prevenir a interferência no período entre 15 e 45 dias após sua emergência (GALON et al., 2010).

No presente experimento, contribuíram para o baixo efeito sobre o rendimento de grãos, provavelmente, a elevada capacidade do híbrido de milho utilizado para suportar a competição com as plantas de UROPL, as boas condições de fertilidade e disponibilidade hídrica a que a área experimental esteve submetida.

\section{CONCLUSÃO}

A eficiência agronômica das formulações de atrazina variou entre épocas de avaliação, sendo a formulação comercial mais eficiente em períodos de tempo menores, após a aplicação, e a formulação xerogel mais eficiente em períodos mais tardios após a aplicação. As diferentes doses e formulações empregadas não resultaram em diferenças de rendimento de grãos entre si e em relação às testemunhas infestada e capinada. 


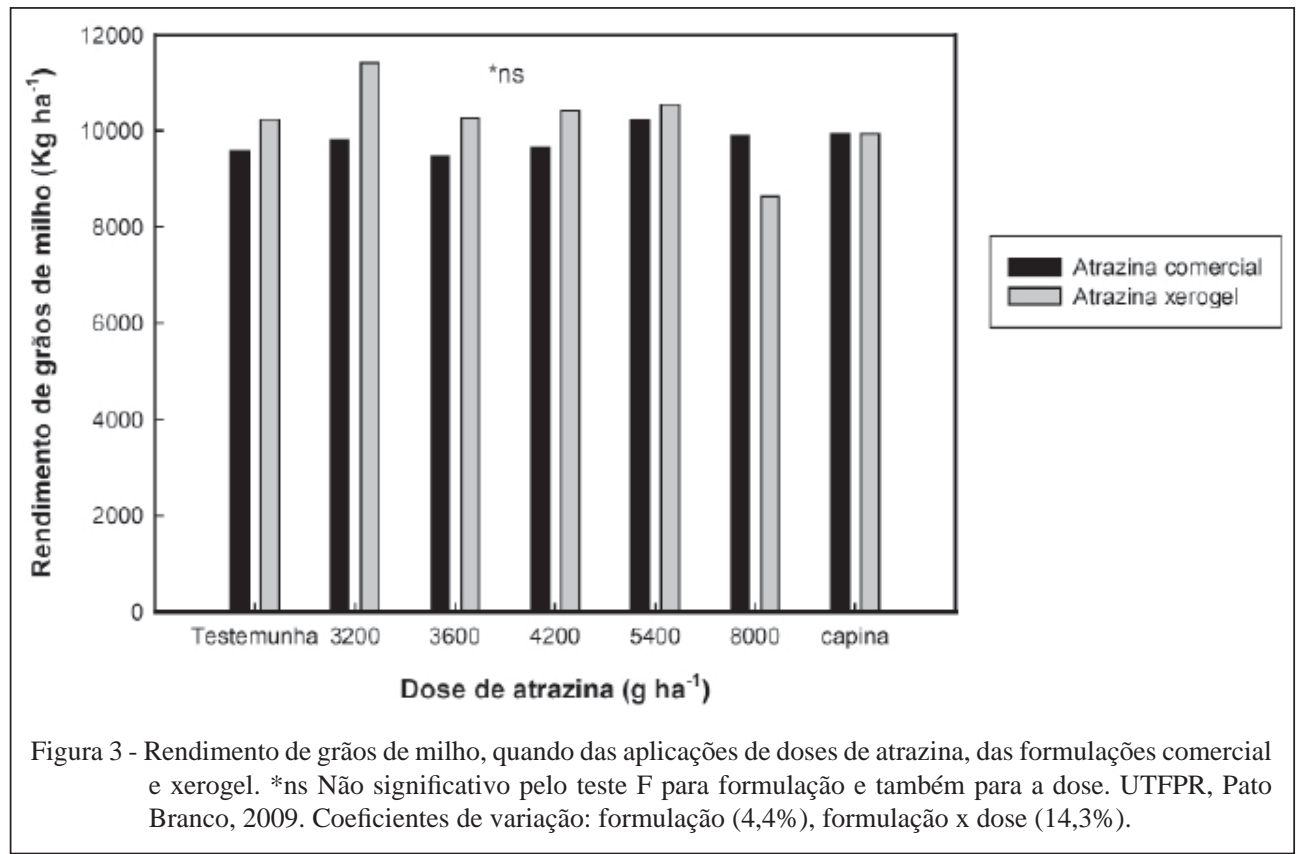

\section{REFERÊNCIAS}

AKELAH, A. et al. Preparation and applications of controlles release systems based on intercaleted atrazine salt and polymeric atrazine salt onto montmorillonite clay. Materials Science and Engineering, v.28, p.1123-1131, 2008. Disponível em: <http:// dx.doi.org/10.1016/j.msec.2007.05.005>. Acesso em: 20 nov. 2010. doi: 10.1016/j.msec.2007.05.005.

ÁVILA, L.G. et al. Formulações de atrazina em xerogéis: síntese e caracterização. Química Nova, v.32, n.7, p.1727-1733, 2009. Disponível em: <http://www.scielo.br/scielo.php?pid=S010040422009000700009\&script=sci_arttext $>$. Acesso em: 22 out. 2010. doi: 10.1590/S0100-40422009000700009.

BALBINOT JR, A.A. et al. Integração lavoura-pecuária: intensificação de uso de áreas agrícolas. Ciência Rural, v.39, n.6, p.1925-1933, 2009. Disponível em: <http://www.scielo.br/pdf/ cr/2009nahead/a229cr838.pdf>. Acesso em: 15 out. 2010.

BARBOSA, D.B.P. et al. Atrazina na formulação xerogel: análise da eficiência agronômica em comparação com a formulação comercial. In: CONGRESSO BRASILEIRO DA CIÊNCIA DAS PLANTAS DANINHAS, 27., 2010, Ribeirão Preto, SP. Resumos expandidos... Ribeirão Preto: Centro de Convenções, 2010. p.3456- 3460.

CERDEIRA, A.L. et al. Lixiviação de atrazina em solo em área de recarga do aquífero guarani. Revista Brasileira de Herbicidas, v.4, n.1, p.99-101, 2005. Disponível em: <http:// www.rbherbicidas.com.br/index.php/rbh/article/view/29>. Acesso em: 26 abr. 2009.

EMBRAPA (EMPRESA BRASILEIRA DE PESQUISA AGROPECUÁRIA). Sistema brasileiro de classificação de solos. Rio de Janeiro: EMBRAPA/CNPSO, 2006. 412p.

FERNÁNDEZ-PÉREZ, M. et al. Mobility of atrazine from alginate-bentonite controlled release formulations in layered soil. Chemosphere, v.43, p.347-353, 2001.
FLECK, N.G.; VIDAL, R.A. Inibidores do fotossistema 2. In: VIDAL R.A.; MEROTTO Jr, A. Herbicidologia. Porto Alegre: Evangraf, 2001. p.100-112.

FRANS, R. et al. Experimental design and techniques for measuring and analyzing plant responses to weed control practices. In: CAMPER, N.D. Research methods in weed science. Champaign: Weed Science, 1986. p.29-46.

GALON, L. et al. Avaliação do método químico de controle de papuã (Brachiaria plantaginea) sobre a produtividade do milho. Pesquisa Agropecuária Tropical, v.40, n.4, p.414-421, 2010. Disponível em: <http://www.revistas.ufg.br/index.php/pat/ issue/view/943>. Acesso em: 08 nov. 2012. doi: 10.5216/pat. v40i4.5170.

KOZLOWSKI, L.A. et al. Épocas e extensões do período de convivência das plantas daninhas interferindo na produtividade da cultura do milho (Zea mays). Planta Daninha, v.27, n.3, p.481490, 2009. Disponível em: <http://www.scielo.br/scielo.php?pid=S 010083582009000300008\&script=sci_abstract\&tlng=pt $>$. Acesso em: 04 maio, 2011. doi: 10.1590/S0100-83582009000300008.

LÓPEZ-OVEJERO, R.F. et al. Seletividade de herbicidas para a cultura de milho (Zea mays) aplicados em diferentes estádios fenológicos da cultura. Planta Daninha, v.21, n.3, p.413-419, 2003. Disponível em: <http://www.scielo.br/scielo.php?script=sci artte xt\&pid=S0100-83582003000300009>. Acesso em: 15 dez. 2010. doi: 10.1590/S0100-83582003000300009.

MEROTTO A. et al. Redução da interferência de Brachiaria plantaginea (link) Hitch. em milho através de capinas e aplicação de herbicidas em diferentes épocas. Planta Daninha, v.18, n.3, p.471-477, 2000. Disponível em: <http://www.scielo.br/scielo. php?script $=$ sci_issuetoc $\&$ pid $=0100835820000003 \& \operatorname{lng}=$ en \&nrm =iso $>$. Acesso em: 23 maio, 2011.

PESSOA, M.C.P.Y. et al. Identificação de áreas de exposição ao risco de contaminação de águas subterrâneas pelos herbicidas

Ciência Rural, v.43, n.11, nov, 2013. 
atrazina, diuron e tebutiuron. Pesticidas: Revista Ecotoxicologia e Meio Ambiente, v.13, p.111-122, 2003. Disponível em: <http://ojs.c3sl.ufpr.br/ojs2/index.php/pesticidas/article/ view/3171/2544>. Acesso em: 23 maio, 2009.

RITCHIE, S.W. et al. How a corn plant develops. Ames: Iowa State University of Science and Technology, Cooperative Extension Service, 1993. 21p. (Special Report, 48). Disponível em: <www.maize.agron.iastate.edu/corngrows.html>. Acesso em: 27 jul. 2011.

SALES, J.L. Determinação dos períodos de interferência e integração de práticas culturais com herbicidas no controle de plantas daninhas na cultura do milho (Zea mays L.). 1991. 151f. Tese (Doutorado em Fitotecnia) - Curso de Pós-graduação em Agronomia, ESALQ - USP, Piracicaba, SP.

SOUZA, J.A. Estudo da biodegradação do ácido 2,4-diclorofenoxiacético em formulações de liberação controlada. 1999. 88f. Tese (Doutorado em Química) Universidade Estadual de Campinas, Campinas, SP.

SPADER, V.; VIDAL, R.A. Interferência de Brachiaria plantaginea sobre características agronômicas, componentes do rendimento e produtividade de grãos de milho. Planta Daninha, v.18, p.465-470, 2000. Disponível em: <http://www.scielo. br/scielo.php?pid=S0100-83582000000300011\&script=sci_ arttext>. Acesso em: 14 mar. 2011. doi: 10.1590/S010083582000000300011 .

TESTA, V.; SILVESTRO, M. Situação eperspectivas socioeconômicas para o milho. In: WORDELL FILHO, J.; ELIAS, H. A cultura do milho em Santa Catarina. Florianópolis: Epagri, 2010. p.7-46.

TREZZI, M.M. et al. Eficácia de controle de plantas daninhas e toxicidade ao milho da mistura de foramsulfuron e iodosulfuron isoladamente ou em associação com atrazine e/ ou clorpirifós. Planta Daninha, v.23, n.4, p.653-659, 2005. Disponível em: <http://www.scielo.br/scielo.php?pid=S010083582005000400013\&script=sci_arttext $>$. Acesso em: 07 jun. 2009. doi: 10.1590/S0100-83582005000400013.

VIDAL, R.A. et al. Nível de dano econômico de Brachiaria plantaginea na cultura de milho irrigado. Planta Daninha, v.22, p.63-69, 2004. Disponível em: <http://www.scielo.br/ scielo.php?pid=S0100-83582004000100008\& script $=$ sci arttext>. Acesso em: 07 jun. 2009. doi: 10.1590/S010083582004000100008 .

ZAGONEL, J. et al. Efeitos de métodos e épocas de controle das plantas daninhas na cultura do milho. Planta Daninha, v.18, p.143-150, 2000. Disponível em: <http://dx.doi.org/10.1590/ S0100-83582000000100014>. Acesso em: 22 nov. 2010. doi: $10.1590 /$ S0100-83582000000100014. 